\title{
Reprinted from:
}

JOURNAL OF NUCLEAR MATERIALS - JOURNAL DES MATERIAUX NUCLEAIRES

VOLUMEE $45(1972 / 1973)$ No. 2

W. SCHIKARSKI and G. ONDRACEK

MEASUREMENTS ABOUT THE EFFECT OF GRAIN BOUNDARIES ON THE ELECTRICAL RESISTIVITY OF URANIUM DIOXIDE

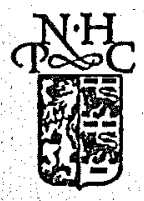

NORTH-HOLLAND PUBLISHING COMPANY - AMSTERDAM 


\section{LETTERS TO THE EDITORS - LETTRES AUX REDACTEURS}

\section{MEASUREMENTS ABOUT THE EFFECT OF GRAIN BOUNDARIES ON THE ELECTRICAL RESISTIVITY OF URANIUM DIOXIDE}

W. SCHIKARSKI and G. ONDRACEK

Institut für Angewandte Reaktorphysik, Institut für Material- und F'estkörperforschung, Kernforschungszentrum Karlsruhe, Germany

Received 10 September 1972

One of the reasons for the scattering in electrical resistivity data of $\mathrm{UO}_{2}$ (up to 4 orders of magnitude at room temperature $\left.{ }^{1}\right)$ ) may be the difference in grain size. To find out to what extent grain boundaries can affect the $\mathrm{UO}_{2}$ electrical resistivity the following measurements have been made. Two types of $\mathrm{UO}_{2}$ specimens having different grain sizes have been used, the chemical analysis and stoichiometry of which were very similar (UO ratios: 1.96 for coarser grain; 1.98 for finer grain). Starting with the same powder, the compacts have been prepared by extrusion $\left(\varrho=10.69 \mathrm{~g} / \mathrm{cm}^{3} \cong 97.6 \%\right.$ TD). Different heat treatments led to the different microstructures shown in fig. 1. A rough stereometric analysis using Tomkeiff's
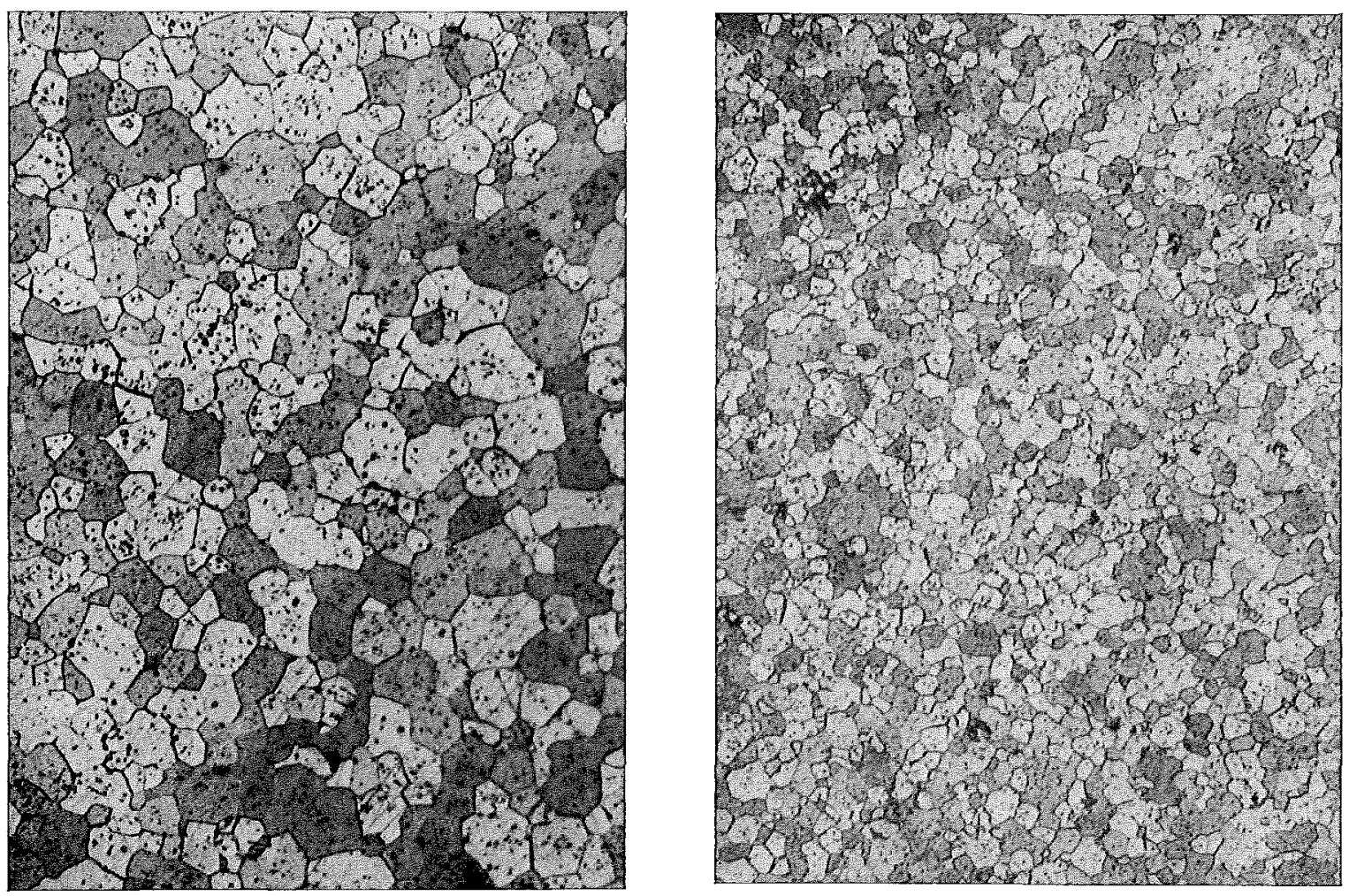

Fig. 1. Mierostructure of coextruded $\mathrm{UO}_{2}$ with different grain size; etchant: $\mathrm{HCL}+\mathrm{HNO}_{3}(1: 1)$. $\times 450$ 
equation ${ }^{2}$ )

$$
S_{\mathrm{V}}=\frac{2}{\bar{L}}
$$

( $\bar{L}=$ measured mean intercept length) shows that the total internal surface (grain boundary area) per unit test volume of $\mathrm{UO}_{2}\left(S_{\mathrm{v}}\right)$ is approximately twice as large in the fine grained $\mathrm{UO}_{2}$ as in the coarser one (fig. 1). Three specimens of each type of microstructure have been used for measuring the temperature dependence of the electrical resistivity. The resulting curves are shown in fig. 2 demonstrating: that the electrical resistivity of the coarser grained $\mathrm{UO}_{2}$ is approximately one order of magnitude higher than that of the finer grained $\mathrm{UO}_{2}$ at all temperatures in the measured range.

Due to the different heat treatments of the specimens they should also have different amounts of lattice defects. This - as well as the different microstructure - could be the reason for the difference in the electrical resistivity.
Lattice defects, however, would create an effect opposite to that shown in fig. 2: the finer grained material should have the higher resistivity because of the higher concentration of lattice defects. Consequently, one can assume that the difference in the electrical resistivity shown here comes from the different grain size. Because of the high electrical resistivity of the $\mathrm{UO}_{2}$ crystallites the conductivity of the bulk material is improved by the grain boundaries. These results were observed for polycrystalline $\mathrm{NaCl}$ [ref. $\left.{ }^{3}\right)$ ] as well as for $\mathrm{Al}_{2} \mathrm{O}_{3}$ [ref. $\left.{ }^{4}\right)$ ], although in the latter case of $\mathrm{Al}_{2} \mathrm{O}_{3}$ other workers ${ }^{5}$ ) have reported low grain boundary conductivity. Both results, higher as well as lower grain boundary conductivity, can be explained in terms of "binder material" in the grain boundaries of $\mathrm{Al}_{2} \mathrm{O}_{3}$ changing the electron affinity between the grain boundary and the crystal ${ }^{6,7}$ ). No conclusion can be drawn from the present results as to whether this effect occurs in $\mathrm{UO}_{2}$. In spite of the clear results here, it cannot be

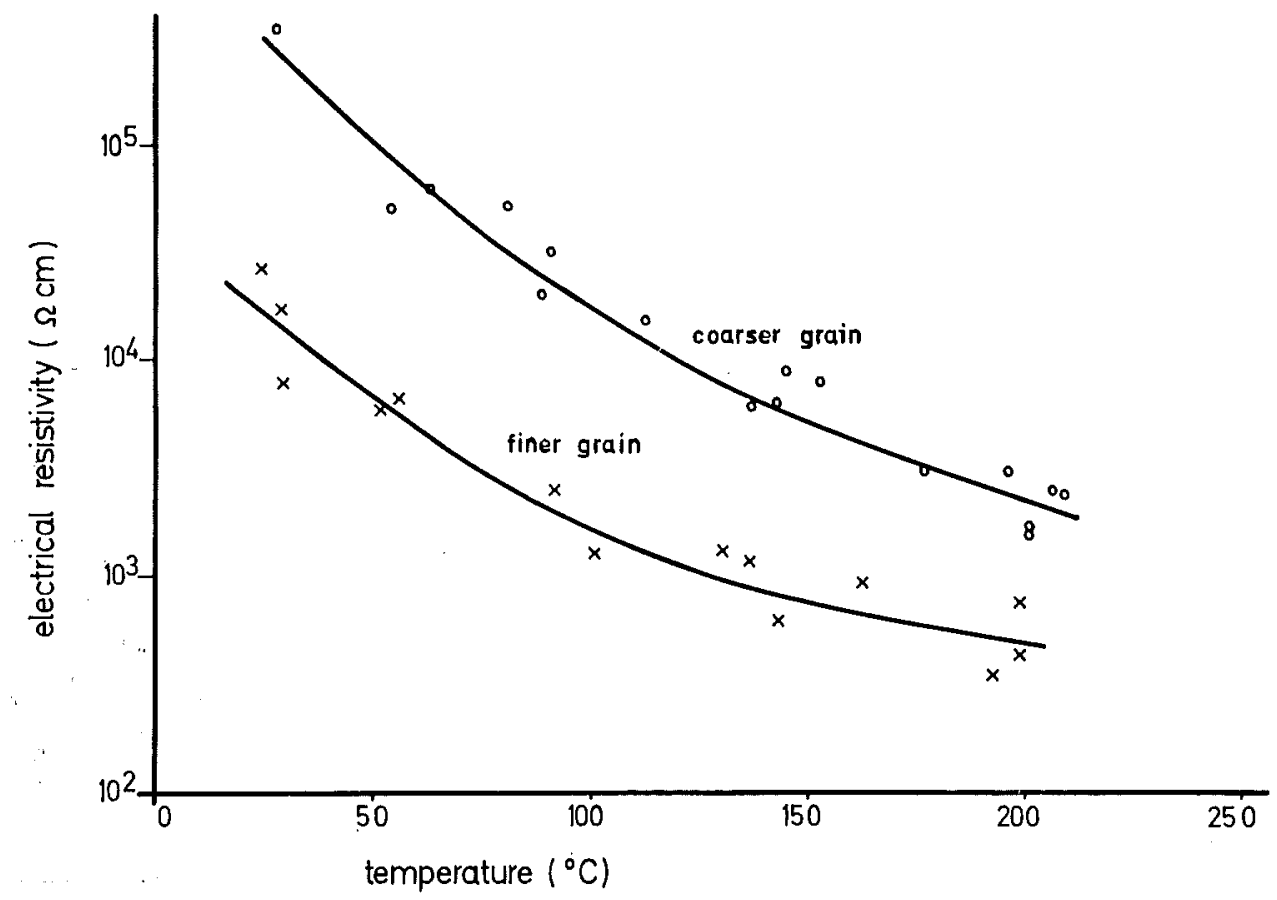

Fig. 2. Electrical resistivity of $\mathrm{UO}_{2}$ specimens with different grain size. 


\section{stated generally, that the grain boundary References}

conductivity of $\mathrm{UO}_{2}$ at lower temperatures is always higher than that of the crystals.

\section{Acknowledgements}

The authors gratefully acknowledge the help of Mr. Bürkin and Mr. Rühl in this work.
1) J. S. Touloukian, Thermophysical Properties of High Temperature Solid Materials, vol. 4 (The McMillan Company, New York, 1967)

2) E. E. Underwood, Quantitative Stereology (Addison Wesley, London, 1970) p. 34

3) H. C. Graham, N. M. Tallan and R. Russell, J. Am. Ceram. Soc. 50 (1967) 156

4) J. Cohen, Am. Ceram. Soc. Bull. 38 (1959) 441

5) J. F. Florio, J. Am. Ceram. Soc. 43 (1960) 262

$\left.{ }^{6}\right)$ O. W. Peters, J. Am. Ceram. Soc. 48 (1965) 220

7) D. W. Peters, J. Am. Ceram. Soc. 48 (1965) 650 
